\title{
Hypoxia diminishes the protective function of white-matter astrocytes in the developing brain
}

\author{
Kota Agematsu, MD, a,b Ludmila Korotcova, MD, ${ }^{\text {a,b }}$ Paul D. Morton, PhD, ${ }^{\text {a,b }}$ Vittorio Gallo, PhD, \\ Richard A. Jonas, MD, ${ }^{\mathrm{a}, \mathrm{b}}$ and Nobuyuki Ishibashi, MD ${ }^{\mathrm{a}, \mathrm{b}}$
}

\begin{abstract}
Objectives: White-matter injury after surgery is common in neonates with cerebral immaturity secondary to in utero hypoxia. Astrocytes play a central role in brain protection; however, the reaction of astrocytes to hypothermic circulatory arrest (HCA) remains unknown. We investigated the role of astrocytes in white-matter injury after HCA and determined the effects of preoperative hypoxia on this role, using a novel mouse model.
\end{abstract}

Methods: Mice were exposed to hypoxia from days 3 to 11 , which is equivalent to the third trimester in humans (prehypoxia, $\mathrm{n}=49$ ). Brain slices were transferred to a chamber perfused by cerebrospinal fluid. Oxygen-glucose deprivation (OGD) was performed to simulate ischemia-reperfusion/reoxygenation resulting from circulatory arrest under hypothermia. Astrocyte reactions were compared with preoperative normoxia (prenormoxia; $n=45$ ).

Results: We observed astrocyte activation after $25^{\circ} \mathrm{C}$ ischemia-reperfusion/ reoxygenation in prenormoxia $(P<.01)$. Astrocyte number after OGD correlated with caspase- $3^{+}$cells (rho $=.77, P=.001$ ), confirming that astrogliosis is an important response after HCA. At 3 hours after OGD, astrocytes in prenormoxia had already proliferated and become activated $(P<.05)$. Conversely, astrocytes that developed under hypoxia did not display these responses. At 20 hours after ischemia-reperfusion/reoxygenation, astrogliosis was not observed in prehypoxia, demonstrating that hypoxia altered the response of astrocytes to insult. In contrast to prenormoxia, caspase $-3^{+}$cells in prehypoxia increased after ischemia reperfusion/reoxygenation, compared with control $(P<.01)$. Caspase $-3^{+}$cells were more common with prehypoxia than with prenormoxia $(P<.001)$, suggesting that lack of astrogliosis permits increased white-matter injury.

Conclusions: Preoperative hypoxia alters the neuroprotective function of astrocytes. Restoring this function before surgery may be a therapeutic option to reduce postoperative white-matter injury in the immature brain. ( $\mathrm{J}$ Thorac Cardiovasc Surg 2016;151:265-72)

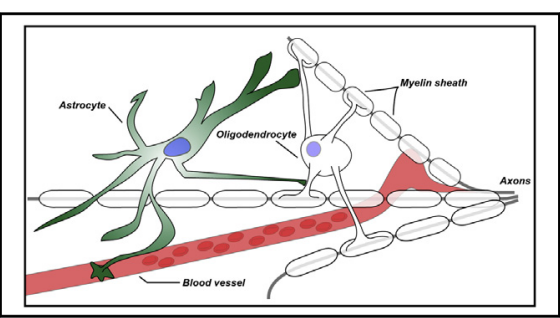

Interaction between astrocytes and oligodendrocytes in the white matter.

Central Message

Astrocyte activation is critical in protecting white matter. Restoration of this function, which is altered by preoperative hypoxia, may reduce postoperative white-matter injury in neonates with $\mathrm{CHD}$

\section{Perspective}

We have demonstrated for the first time that astrocyte activation plays a critical role in white-matter protection. The reaction is altered after hypoxia, and thus contributes to increased white-matter injury after neonatal cardiac surgery. Restoring the neuroprotective function before surgery can be targeted to reduce postoperative white-matter injury in the neonate with CHD

See Editorial Commentary page 273.

\footnotetext{
From the a Children's National Heart Institute; and ${ }^{\mathrm{b}}$ Center for Neuroscience Research, Children's National Medical Center, Washington, DC.

This work was supported in part by National Institutes of Health grants R01HL104173 and R01HL128546 (to R.A.J) and R01NS045702 (to V.G.), The Intellectual and Developmental Disabilities Research Center P30HD40677 (to V.G.), Baier Cardiac Research Fund (to R.A.J), and Children's Research Institute Neonatal Brain Injury Project (to V.G. and N.I.).

Received for publication May 19, 2015; revisions received Aug 17, 2015; accepted for publication Aug 23, 2015; available ahead of print Sept 26, 2015.

Address for reprints: Nobuyuki Ishibashi, MD, Children's National Heart Institute and Center for Neuroscience Research, Children's National Medical Center, 111 Michigan Ave, N.W., Washington, DC 20010-2970 (E-mail: nishibas@ childrensnational.org).

$0022-5223 / \$ 36.00$

Copyright (c) 2016 by The American Association for Thoracic Surgery

http://dx.doi.org/10.1016/j.jtcvs.2015.08.076
}

Supplemental material is available online.

Neurodevelopmental delay has become recognized as one of the most important challenges for children with surgically repaired congenital heart disease (CHD). ${ }^{1}$ Clinical studies have demonstrated an important incidence of white-matter injury in children with CHD. ${ }^{2-6}$ Abnormal white-matter development early in life accounts for the type and degree of the neurologic deficits commonly observed in children with CHD. ${ }^{7}$ Thus, elucidating the 


\section{Abbreviations and Acronyms \\ $\mathrm{CHD}=$ congenital heart disease \\ $\mathrm{CPB}=$ cardiopulmonary bypass \\ $\mathrm{GFAP}=$ glial fibrillary acidic protein \\ GFP = green fluorescent protein \\ $\mathrm{HCA}=$ hypothermic circulatory arrest \\ OGD = oxygen-glucose deprivation \\ PBS = phosphate buffered saline}

cellular mechanisms underlying CHD-induced whitematter injury is not only a fundamental research endeavor, but also vital for the design of targeted therapies and conditions to improve such disorders.

Although previous clinical trials and laboratory research have focused on white-matter injury that occurs during surgery, and cardiopulmonary bypass (CPB), new evidence from neuroimaging studies has additionally linked CHD with white-matter immaturity in the fetus during the prenatal period. ${ }^{8,9}$ The basic structural morphology of the heart is complete by 7 weeks of gestation. Thus, a cardiac anomaly can affect fetal cerebral oxygen saturation for $>7$ months, a period of critical importance to brain development. Newly developed postoperative white-matter injury has been demonstrated to be significantly associated with preoperative white-matter immaturity. ${ }^{4,10}$ However, cellular events secondary to CHD-induced hypoxia, and the impact of cardiac surgery on these events in developing white matter, remain largely unexplored.

Reproducing abnormal fetal cerebral blood flow and oxygen saturation observed in CHD patients is challenging in large laboratory animals. However, a rodent model has been well established, of chronic hypoxia during the period of early postnatal development, which is equivalent to the third trimester in humans. ${ }^{11-13}$ Hypothermic circulatory arrest (HCA) and $\mathrm{CPB}$ can cause major brain insults during surgery. ${ }^{2,8}$ The HCA poses a specific pathologic condition for patients undergoing cardiac surgery: exposure to ischemia-reperfusion/reoxygenation under hypothermia. Using a unique rodent brain-slice model, we have replicated specific brain conditions of $\mathrm{CPB}$ and HCA. ${ }^{14}$

To understand the complex pathology of CHD-induced white-matter injury, we have additionally established a combined experimental paradigm of prenatal hypoxia and HCA in a mouse hypoxia and brain-slice model. ${ }^{15}$ Using this model, we recently demonstrated that white-matter immaturity caused by preoperative hypoxia causes increased vulnerability of oligodendrocyte lineage cells to hypothermic ischemia-reperfusion/reoxygenation. ${ }^{15}$

Astrocytes are the most numerous cells in the mammalian brain, and they make essential contributions to normal function in the healthy brain, including regulation of blood flow, provision of energy metabolites, and maintenance of the extracellular balance of fluid and neurotransmitters. ${ }^{16}$ In addition, astrocytes react to all forms of brain insults, and their response-commonly referred to as reactive astrogliosis-is a hallmark of all central nervous system pathologies. ${ }^{17}$ The crucial role of reactive astrogliosis in white-matter injury has been well documented, ${ }^{18,19}$ yet little is known regarding the reaction of astrocytes to the multifaceted insults in CHD brains.

Thus, the overall aim of the present study is to determine the response of white-matter astrocytes to brain injury associated with CHD. Using our unique rodent hypoxia and brain-slice model, we first defined the role of astrocytes in reducing white-matter injury associated with CPB and HCA. We assessed the effects of preoperative hypoxia on both the acute reaction of astrocytes against insults, and their protective role.

\section{METHODS}

\section{Animals}

A total of 83 mice were involved in this study. We used a transgenic human glial fibrillary acidic protein (GFAP)/green-fluorescent protein (GFP) mouse (The Jackson Laboratory, Bar Harbor, Me) to identify white-matter astrocytes (Figure 1, A). Astrocytes have been visualized in transgenic mice, in which the GFAP promoter region directs expression of GFP. To investigate the effects of preoperative hypoxia, animals aged 3 days were randomly assigned to 1 of 2 preoperative conditions: (1) prenormoxia $(n=49)$; and (2) prehypoxia $(n=34)$.

The effects of brain insults associated with CPB and HCA on white-matter astrocytes were investigated in day-11 mice, which have a white-matter maturation level equivalent to that of the human full-term newborn (Figure 1, B). ${ }^{20}$ The living brain slices collected from transgenic mice at day 11 were perfused, using artificial cerebrospinal fluid, and assigned to 1 of 4 groups with various levels of brain insult associated with HCA: (1) control (no OGD); (2) $15^{\circ} \mathrm{C}$ OGD for 60 minutes; (3) $25^{\circ} \mathrm{C}$ OGD for 60 minutes; and (4) $35^{\circ} \mathrm{C}$ OGD for 60 minutes (Table E1). Brains in each group were fixed at 3 hours and 20 hours after rewarming, respectively (Figure 1, $C$ ). We performed all experiments in compliance with the National Institutes of Health Guide for the Care and Use of Laboratory Animals. The study was approved by the Animal Care and Use Committee of the Children's National Medical Center. More details are described in Appendix E1.

\section{Preoperative Hypoxia}

The hypoxic rearing began on day 3 and continued until day 11 in a hypoxic chamber system (BioSpherix, Redfield, NY) to reproduce the preoperative hypoxic state (prehypoxia, $10.5 \%$ oxygen) of the CHD fetus (Figure 1,B). ${ }^{13}$ The maturation stage from day 3 to day 11 in the mouse white matter is developmentally equivalent to the third trimester in humans. ${ }^{20} \mathrm{~A}$ recent clinical magnetic resonance imaging (MRI) study revealed that during the third trimester, a progressive and significant decline occurs in gestational age-adjusted white-matter volume in CHD fetuses, compared with healthy controls. ${ }^{21}$ Strain- and age-matched mice that were reared in a setting with normal oxygen levels were used to simulate a preoperative normoxic condition (prenormoxia; $21 \%$ oxygen). More details are described in Appendix E1.

\section{Perfusion Protocol}

Brains of transgenic mice at day 11 were collected. Living brains were sliced, using a vibratome (Leica 1200 VT; Leica Microsystems, Inc, 

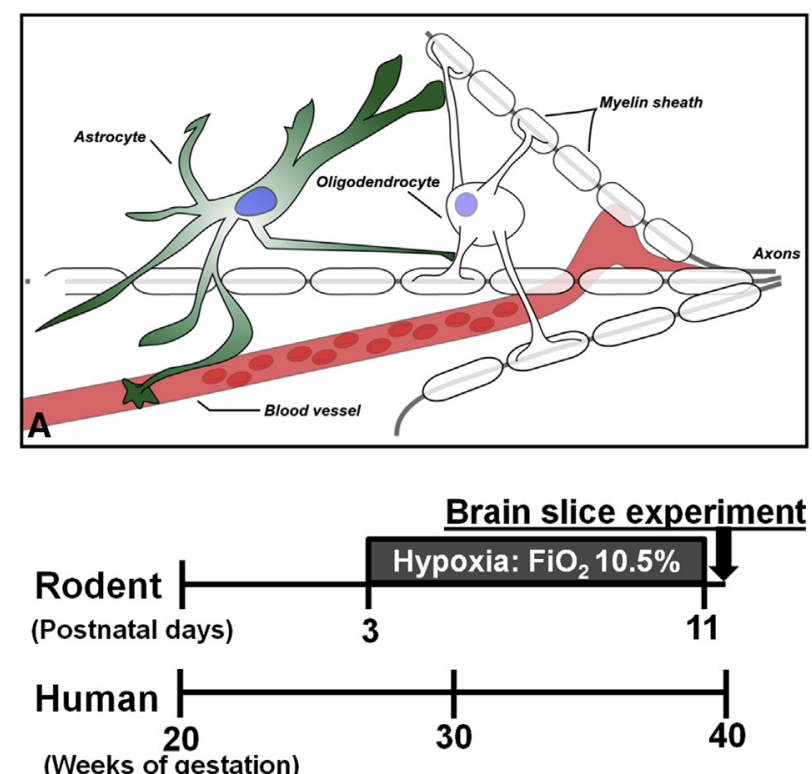

B

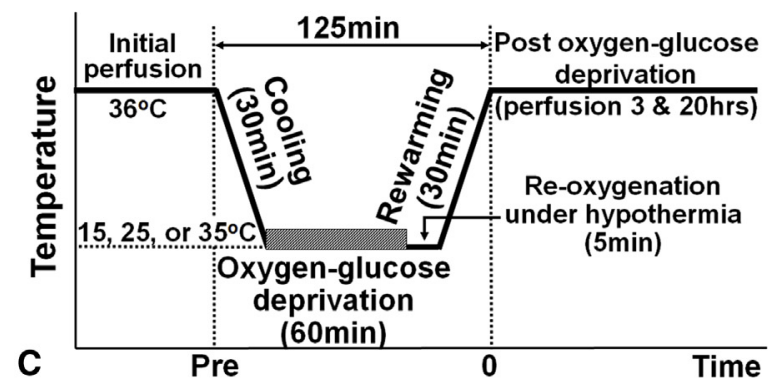

FIGURE 1. A, Interaction between astrocytes and oligodendrocytes in white matter. B, Study design and equivalent time period for whitematter development between the mouse and human. C, Perfusion protocol for oxygen-glucose deprivation under hypothermia to replicate brain conditions under hypothermic circulatory arrest.

Buffalo Grove, Ill). Only slices containing corpus callosum, which is a major white-matter structure in the mouse brain, were included in the experiments. After the initial recovery period from the slice procedure, brains were cooled to a temperature of $15^{\circ} \mathrm{C}, 25^{\circ} \mathrm{C}$, or $35^{\circ} \mathrm{C}$ for 30 minutes, according to the protocol (Figure 1,C). The OGD was performed afterward, for 60 minutes at 1 of 3 temperature settings. After the deprivation, slices were reperfused with glucose-containing artificial cerebrospinal fluid saturated with $95 \% \mathrm{O}_{2} / 5 \% \mathrm{CO}_{2}$, for 5 minutes, followed by a 30 -minute rewarming period (Figure 1,C). This process replicates HCA-induced hypothermic ischemia-reperfusion/reoxygenation.

Damage to white-matter astrocytes in brain slices was assessed at 3 and 20 hours after rewarming (Figure 1,C). Control slices that were perfused at $36^{\circ} \mathrm{C}$ with artificial cerebrospinal fluid saturated with $95 \% \mathrm{O}_{2} / 5 \% \mathrm{CO}_{2}$ for the same duration (no OGD) were used for comparison with the deprivation groups. The details of the brain-slice preparation and perfusion methods are described in Appendix E1 and our previous publications. ${ }^{14,15}$

\section{Assessments of White-Matter Cellular Damage}

For assessment of white-matter astrocyte injury, 20- $\mu \mathrm{m}$ sections were obtained from each $400-\mu \mathrm{m}$ brain slice, using a Cryotome (Microm
HM525; Thermo Scientific, Waltham, Mass). For immunohistochemistry, $20-\mu \mathrm{m}$ sections were incubated with primary antibody, followed by secondary antibody. A well established finding is that, in response to adult brain injury, astrocytes become activated and convert to a reactive phenotype, which is characterized by increased GFAP expression, and changes in the cell morphology and proliferation rate. ${ }^{22,23}$ We identified astrocyte activation using an antibody to the GFAP, as we have done previously. ${ }^{12}$ Cell proliferation was identified using antibodies to Ki67. ${ }^{24}$ An antibody to cleaved caspase- 3 was used to identify apoptosis in the white matter. ${ }^{24}$ A Zeiss LSM 510 confocal laser scanning microscopic system (Carl Zeiss Microimaging LLC, Thornwood, NY) was used for the analysis.

Analysis of immunofluorescence was performed on confocal z-stacks. Merged images were processed in Photoshop 7.0 (Adobe Systems, San Jose, Calif), as described elsewhere. ${ }^{14,15,24}$ White-matter injury in astrocytes was assessed by counting $\mathrm{GFP}^{+}$caspase- $3^{+}$cell numbers in $225 \times 225 \times 20 \mu \mathrm{m}$ (X, Y, Z planes) for cell/volume quantifications. To determine cell density, the antibody-positive cells were quantified in 3 microscopic fields from the corpus callosum of each brain, as described previously. ${ }^{14,15}$ More details are described in Appendix E1.

\section{Statistical Analysis}

The nonparametric Kruskal-Wallis $H$ test and the Mann-Whitney $U$ test were used to assess differences in the median numbers of white-matter apoptotic cells, astrocytes, and activated astrocytes among the OGD groups. The Mann-Whitney $U$ test was additionally applied, for comparing prenormoxia and prehypoxia, to assess differences in activated astrocytes and apoptotic cells in white matter. The Spearman rank correlation coefficient (rho) was used to measure the general association between caspase $-3^{+}$apoptotic cells and astrocycle activation in the prenormoxic and prehypoxic groups.

The data distributions are shown as box-and-whisker plots of the median and interquartile range (lower and upper quartiles), because this approach is less sensitive to outliers and skew. Statistical significance was determined by 2 -tailed $P$ value less than .05 . Analysis of the data was performed using IBM/SPSS software, version 19.0 (IBM, Armonk, NY).

\section{RESULTS}

Reactive Astrogliosis Is an Important Cellular Response After Hypothermic Ischemia-Reperfusion/ Reoxygenation

In the prenormoxia group, significant differences were found in white-matter caspase- $3^{+}$cell number among the 3 temperature settings with OGD (Figure E1, $A-D$ ). The numbers were significantly correlated with the temperature during OGD (Figure 1, $A-D$ ). This temperature-dependent injury pattern is similar to that observed in a large-animal HCA model. ${ }^{25}$ These results confirm that our brain-slice model is suitable for investigation of brain injury resulting from HCA in GFAP/GFP transgenic mice, as we demonstrated using another transgenic mouse line ${ }^{14}$ (Figure E1, $A-D$ ).

We next analyzed the effects of each temperature setting on astrocyte injury at 20 hours after OGD. A significant increase was found in caspase- $3^{+}$astrocytes after $35^{\circ} \mathrm{C}$ OGD, compared with the controls, but not after deprivation at $15^{\circ} \mathrm{C}$ or $25^{\circ} \mathrm{C}$ (Figure 2, $H$ ). The morphology of astrocytes was significantly damaged at 20 hours after $35^{\circ} \mathrm{C}$ deprivation, whereas morphologic damage was not observed after deprivation at $15^{\circ} \mathrm{C}$ or $25^{\circ} \mathrm{C}$ (Figure $2, A-D$ ). The highly 


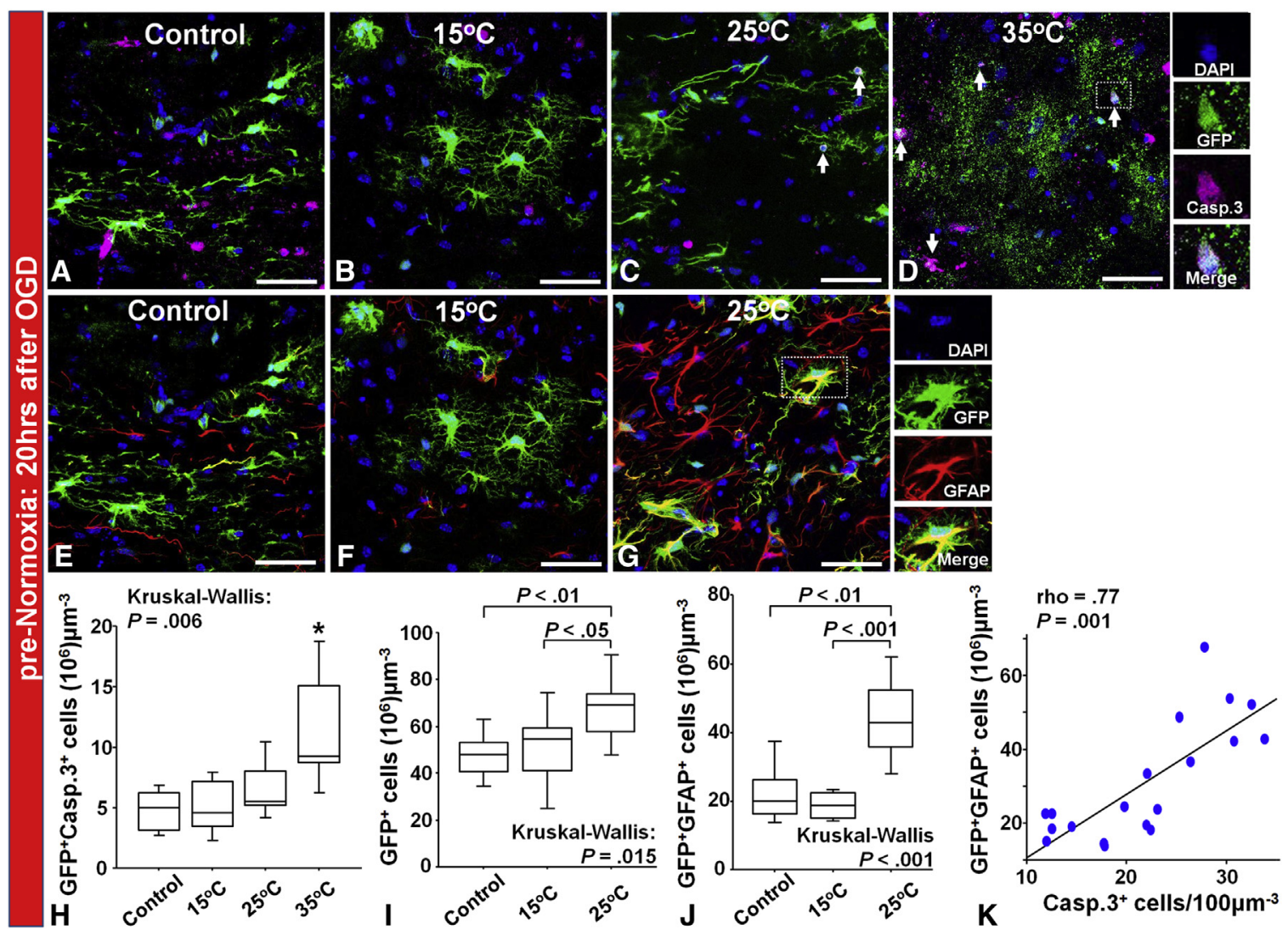

FIGURE 2. Astrogliosis is an important cellular response after hypothermic ischemia-reperfusion/reoxygenation. At 20 hours after oxygen-glucose deprivation: (A-D) morphologic changes and caspase-3 immunostaining in white-matter astrocytes; (E-G) $\mathrm{GFP}^{+} \mathrm{GFAP}^{+}$-activated astrocytes; (H) caspase- $3^{+} \mathrm{GFP}^{+}$apoptotic astrocyte number (control, $\mathrm{n}=9 ; 15^{\circ} \mathrm{C}, \mathrm{n}=10 ; 25^{\circ} \mathrm{C}, \mathrm{n}=9 ; 35^{\circ} \mathrm{C}, \mathrm{n}=6$ ); (I) $\mathrm{GFP}^{+}$astrocyte number (control, $\mathrm{n}=9$; $15^{\circ} \mathrm{C}, \mathrm{n}=10 ; 25^{\circ} \mathrm{C}, \mathrm{n}=9$ ); and $(\mathrm{J}) \mathrm{GFP}^{+} \mathrm{GFAP}^{+}$-activated astrocyte number (control, $\mathrm{n}=9 ; 15^{\circ} \mathrm{C}, \mathrm{n}=10 ; 25^{\circ} \mathrm{C}, \mathrm{n}=9$ ). $\mathrm{K}$, Correlation of numbers between white-matter caspase- $3^{+}$cell and $\mathrm{GFP}^{+} \mathrm{GFAP}^{+}$-activated astrocytes $(\mathrm{n}=19)$. Scale bar $=50 \mu \mathrm{m}$. Data are shown as box-and-whisker plots. $O G D$, Oxygen-glucose deprivation; DAPI, 4',6-diamidino-2-phenylindole; GFP, green fluorescent protein; casp, caspace; GFAP, glial fibrillary acidic protein. $* P<.05$ versus $25^{\circ} \mathrm{C}$; and $P<.01$ versus control and $15^{\circ} \mathrm{C}$, using the Mann-Whitney $U$ test (pairwise testing).

destructive injury seen after deprivation at $35^{\circ} \mathrm{C}$ precluded analysis of astrocyte reaction to insults associated with $\mathrm{CPB}$ and HCA. Therefore, the role of astrocytes on white-matter injury owing to HCA-associated hypothermic ischemiareperfusion/reoxygenation was determined using 3 groups: (1) control; (2) $15^{\circ} \mathrm{C} \mathrm{OGD;} \mathrm{(3)} 25^{\circ} \mathrm{C}$ OGD.

Astrogliosis and astrocyte activation were assessed next. Number of cells that were positive for GFP, or doublepositive for GFP/GFAP revealed significant increases in the numbers of astrocytes and activated astrocytes, respectively, after $25^{\circ} \mathrm{C}$ OGD, compared with controls, but not after deprivation at $15^{\circ} \mathrm{C}$ (Figure $2, G, I$, and $J$ ). In addition, we found a significant positive correlation between caspase- $3^{+}$apoptotic cells and astrocyte activation after ischemia-reperfusion/reoxygenation injury due to OGD (Figure 2, $K$ ). These findings suggest that astrogliosis is an important cellular response after hypothermic ischemia-reperfusion/reoxygenation, as observed with other types of brain damage in the white matter. ${ }^{19}$

\section{Astrocytes That Developed Under Hypoxic Conditions Have an Altered Acute Reaction to a Brain Insult}

We next analyzed the relationship between up-regulation of caspase-3, and astrocyte proliferation in the acute period after ischemia-reperfusion/reoxygenation injury, by evaluating the numbers of caspase- $3^{+}$cells and Ki67 astrocytes at 3 hours after OGD. In this acute period after ischemia-reperfusion/reoxygenation injury, up-regulation of caspase-3 was not significant; in contrast, astrocytes had already proliferated after $25^{\circ} \mathrm{C}$ OGD, but not with $15^{\circ} \mathrm{C}$ OGD. In addition, significant increases occurred in the numbers of astrocytes and activated astrocytes at 3 hours after $25^{\circ} \mathrm{C}$ OGD, indicating that in white matter, astrogliosis occurs before apoptosis, after hypothermic ischemia-reperfusion/reoxygenation (Figure 3, $A-H$ ).

In contrast to these acute responses of astrocytes that developed with normal physiologic conditions (prenormoxia), with prehypoxia, we did not observe any 


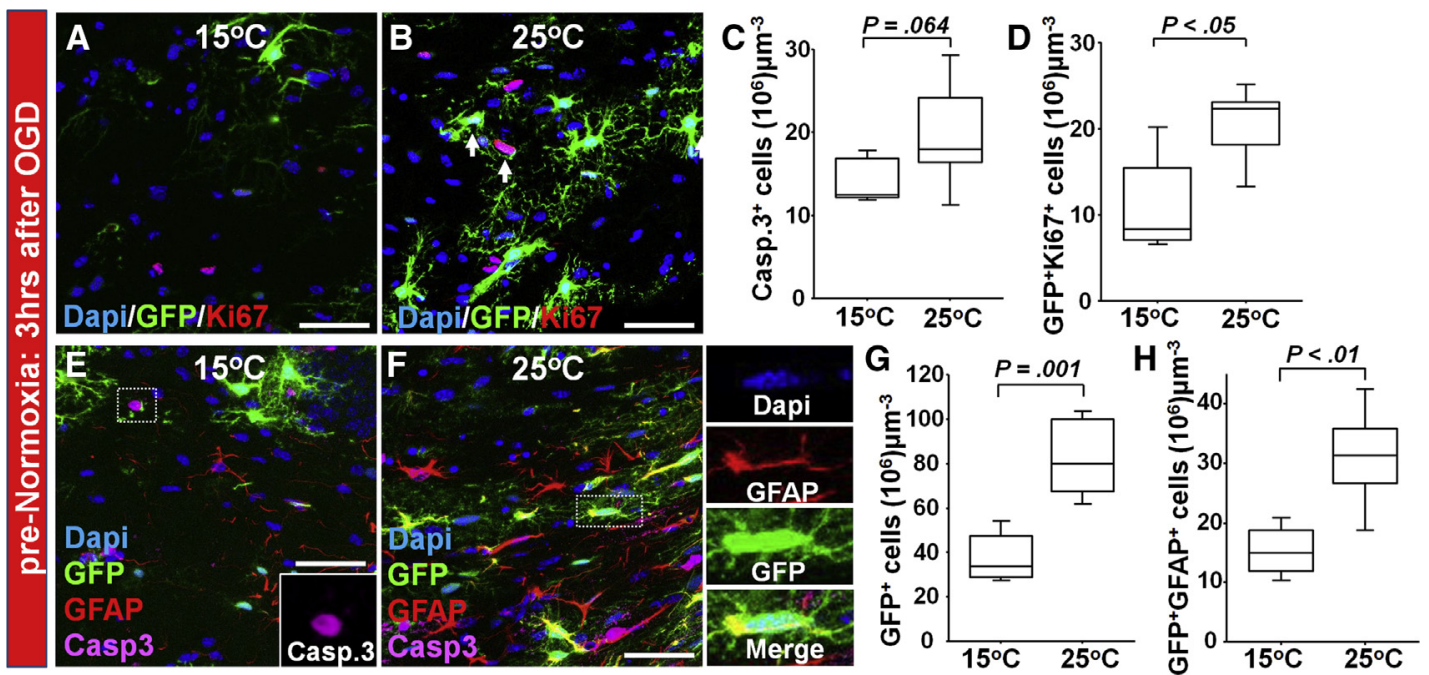

FIGURE 3. White-matter astrogliosis occurs before apoptosis, after hypothermic ischemia-reperfusion/reoxygenation. At 3 hours after OGD: (A and B) $\mathrm{GFP}^{+} \mathrm{Ki} 67^{+}$proliferating astrocytes; (C) caspase- $3^{+}$cell number in the white matter $\left(15^{\circ} \mathrm{C}, \mathrm{n}=7 ; 25^{\circ} \mathrm{C}, \mathrm{n}=8\right)$; (D) $\mathrm{GFP}^{+} \mathrm{Ki}^{+} 7^{+}$proliferating astrocyte number (at $15^{\circ} \mathrm{C}$ and $25^{\circ} \mathrm{C} ; \mathrm{n}=5$ ); (E) caspase- $3^{+}$cells in the white matter; (F) $\mathrm{GFP}^{+} \mathrm{GFAP}^{+}$-activated astrocytes $\left(25^{\circ} \mathrm{C}\right.$ ); $(\mathrm{G}) \mathrm{GFP}^{+}$astrocyte number $\left(15^{\circ} \mathrm{C}, \mathrm{n}=7 ; 25^{\circ} \mathrm{C}, \mathrm{n}=8\right)$; $(\mathrm{H}) \mathrm{GFP}^{+} \mathrm{GFAP}^{+}$-activated astrocyte number $\left(15^{\circ} \mathrm{C}, \mathrm{n}=7 ; 25^{\circ} \mathrm{C}, \mathrm{n}=8\right)$. Scale bar $=50 \mu \mathrm{m}$. Data are shown as box-and-whisker plots. $O G D$, Oxygen-glucose deprivation; DAPI, $4^{\prime}, 6$-diamidino-2-phenylindole; GFP, green fluorescent protein; GFAP, glial fibrillary acidic protein; casp, caspace.

differences in the number of astrocytes, proliferating astrocytes, or activated astrocytes between $15^{\circ} \mathrm{C}$ and $25^{\circ} \mathrm{C}$ at 3 hours after OGD (Figure 4, $A-G$ ). The results demonstrate that astrocytes that develop under hypoxic conditions have a reduced or altered acute reactive response to brain insults.
Preoperative Hypoxia Diminishes Reactive Astrogliosis in Response to Hypothermic IschemiaReperfusion/Reoxygenation

We next assessed the effect of preoperative hypoxia on astrocyte activation against insults, at 20 hours after OGD. In the prenormoxia group, a significant increase in
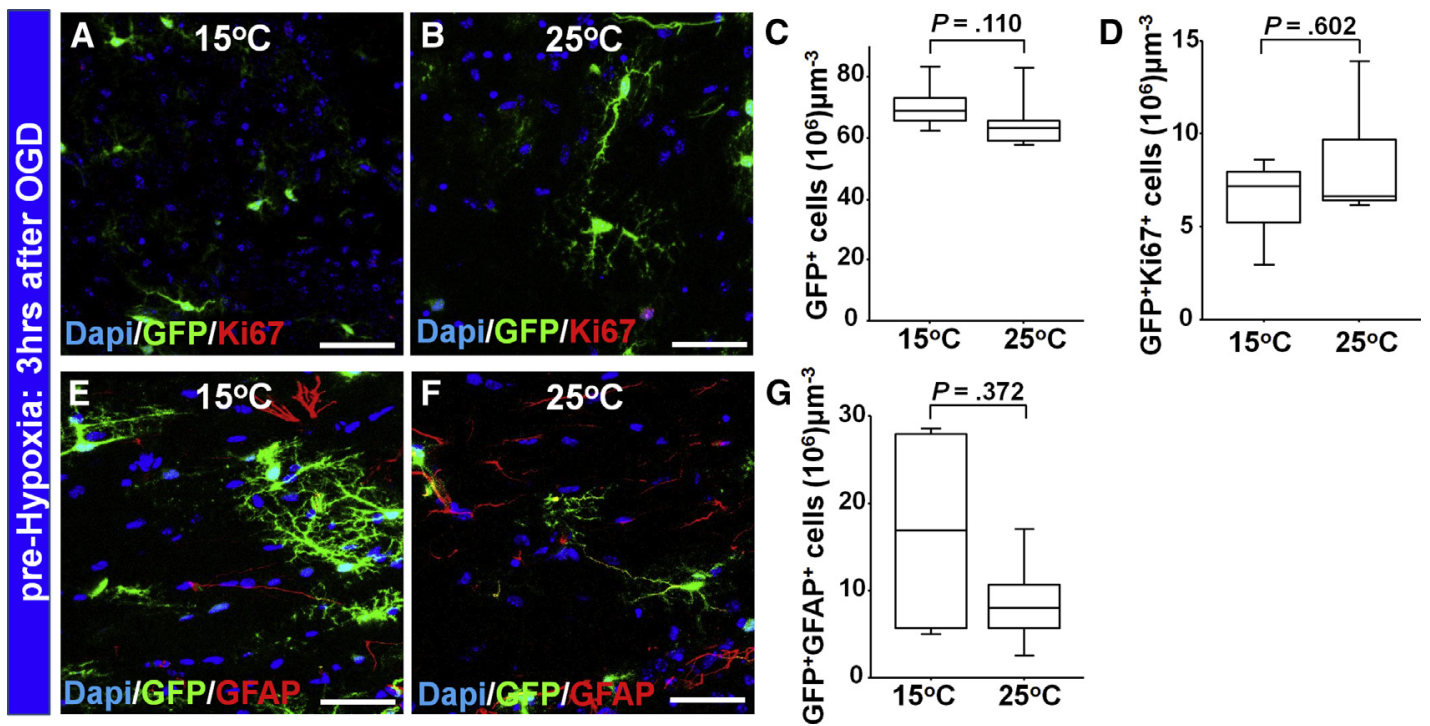

FIGURE 4. Astrocytes that developed under hypoxic conditions alter the acute reactive response after hypothermic ischemia-reperfusion/reoxygenation. At 3 hours after oxygen-glucose deprivation following hypoxia: (A and B) $\mathrm{GFP}^{+} \mathrm{Ki}^{+}$proliferating astrocytes; (C) $\mathrm{GFP}^{+}$astrocyte number $\left(\right.$at $15^{\circ} \mathrm{C}$ and $25^{\circ} \mathrm{C} ; \mathrm{n}=7$ ); (D) $\mathrm{GFP}^{+} \mathrm{Ki}^{+} 7^{+}$proliferating astrocyte number (at $15^{\circ} \mathrm{C}$ and $25^{\circ} \mathrm{C} ; \mathrm{n}=5$ ); E and $\mathrm{F}_{\text {, }} \mathrm{GFP}^{+} \mathrm{GFAP}^{+}$-activated astrocytes; $\mathrm{G}, \mathrm{GFP}^{+} \mathrm{GFAP}^{+}$-activated astrocyte number $\left(\right.$at $15^{\circ} \mathrm{C}, \mathrm{n}=5$; at $25^{\circ} \mathrm{C}, \mathrm{n}=7$ ). Scale bar $=50 \mu \mathrm{m}$. Data are shown as box-and-whisker plots. $O G D$, Oxygen-glucose deprivation; DAPI, 4',6-diamidino-2-phenylindole; GFP, green fluorescent protein; GFAP, glial fibrillary acidic protein. 

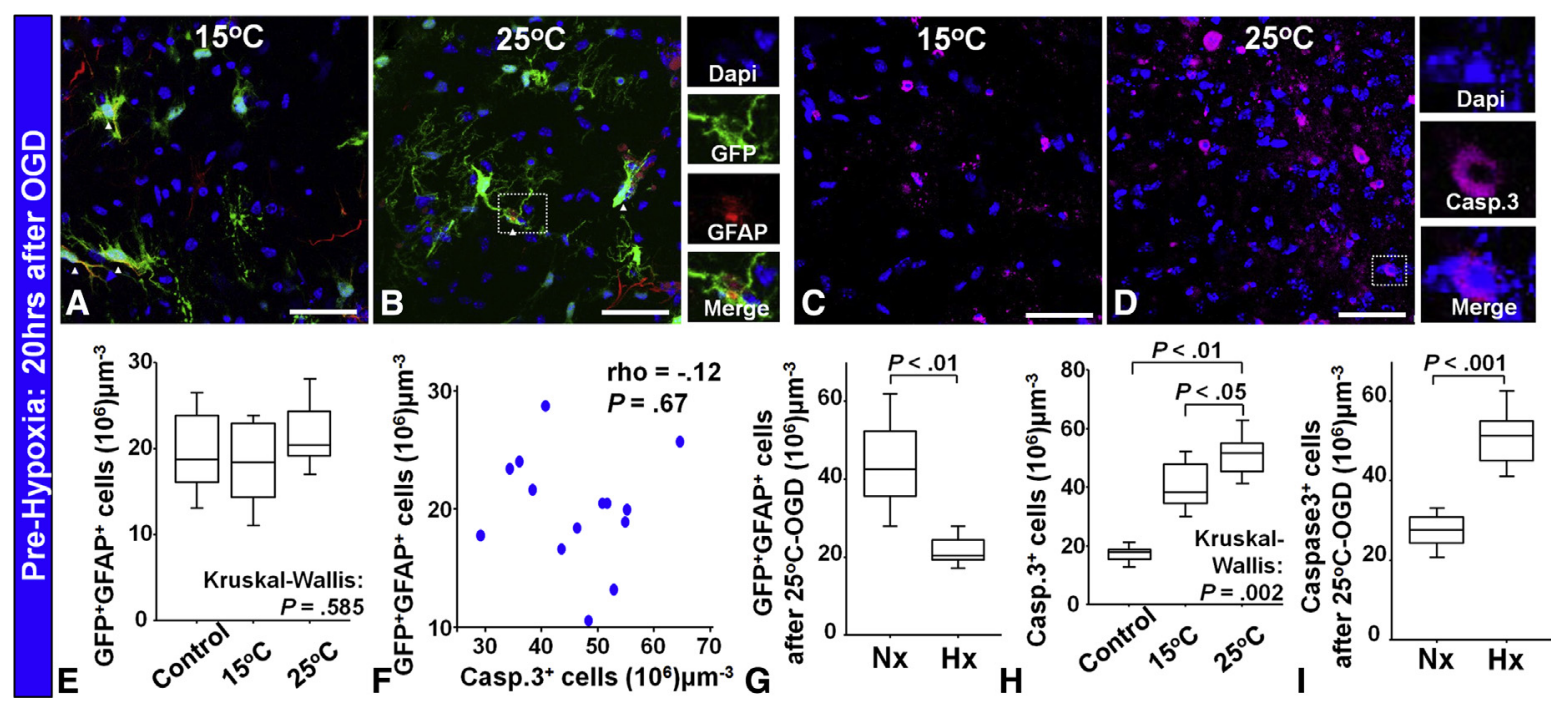

FIGURE 5. Preoperative hypoxia diminishes reactive astrogliosis to hypothermic ischemia-reperfusion/reoxygenation. At 20 hours after OGD following hypoxia: (A and B) $\mathrm{GFP}^{+} \mathrm{GFAP}^{+}$-activated astrocytes; (C and D) white-matter caspase- $3^{+}$cells; (E) $\mathrm{GFP}^{+} \mathrm{GFAP}^{+}$-activated astrocyte number (control, $\mathrm{n}=5$; at $15^{\circ} \mathrm{C}$ and $25^{\circ} \mathrm{C} ; \mathrm{n}=7$ ); (F) correlation between white-matter caspase- $3^{+}$cell and $\mathrm{GFP}^{+} \mathrm{GFAP}^{+}$-activated astrocyte numbers $(\mathrm{n}=14)$; $(\mathrm{G}) \mathrm{GFP}^{+} \mathrm{GFAP}^{+}$-activated astrocyte number $\left(\right.$at $\left.25^{\circ} \mathrm{C}\right)$ between prenormoxia $(\mathrm{n}=9)$ and prehypoxia $(\mathrm{n}=7)$. $(\mathrm{H})$ white-matter caspase- $3^{+}$ cell numbers (control, $\mathrm{n}=5$; at $15^{\circ} \mathrm{C}$ and $25^{\circ} \mathrm{C}, \mathrm{n}=7$ ); and (I) white-matter caspase- $3^{+}$cell numbers $\left(\right.$at $25^{\circ} \mathrm{C}$ ) between prenormoxia ( $\mathrm{n}=9$ ) and prehypoxia $(\mathrm{n}=7)$. Scale bar $=50 \mu \mathrm{m}$. Data are shown as box-and-whisker plots. OGD, Oxygen-glucose deprivation; DAPI, 4',6-diamidino-2-phenylindole; GFP, green fluorescent protein; GFAP, glial fibrillary acidic protein; casp, caspace; $N x$, normoxia; $H x$, hypoxia, but not hydrohia.

activated astrocytes was displayed after $25^{\circ} \mathrm{C}$ OGD, compared with controls, and $15^{\circ} \mathrm{C}$ OGD (Figure 2, J). Conversely, in the prehypoxia group, no significant differences in astrocyte activation were found for the 3 groups (Figure 5, $A, B$, and $E$ ). A positive correlation between apoptotic cells and astrocyte activation was found in prenormoxia at 20 hours after ischemia-reperfusion/reoxygenation injury, owing to OGD (Figure 1, K); however, we did not observe any correlation between these cell populations in the prehypoxia group (Figure $5, F$ ). The number of activated astrocytes after $25^{\circ} \mathrm{C}$ OGD was significantly lower in the prehypoxia group, compared with that for the prenormoxia group (Figure 5, $G)$. Altogether, our results indicate that preoperative hypoxia diminishes reactive astrogliosis in response to brain insults.

In the prenormoxia group, we did not observe an increase in caspase- $3^{+}$cells after $15^{\circ} \mathrm{C}$ and $25^{\circ} \mathrm{C}$ OGD, compared with the control group; conversely, caspase- $3^{+}$ apoptotic cell numbers in prehypoxia increased significantly after both $15^{\circ} \mathrm{C}$ and $25^{\circ} \mathrm{C}$ hypothermic OGD, compared with the control group (Figure 5, $C, D$, and $H$ ). Consistent with these findings, caspase- $3^{+}$cell numbers after $25^{\circ} \mathrm{C}$ OGD were significantly higher with prehypoxia than with prenormoxia (Figure 5, I), suggesting that a lack of astrogliosis is associated with increased white-matter caspase-3 cell numbers after hypothermic ischemia-reperfusion/reoxygenation after preoperative hypoxia.

\section{DISCUSSION}

This study is the first to identify reactive astrogliosis after hypothermic ischemia-reperfusion/reoxygenation injury using a mouse brain-slice model that reproduces the brain environment during CPB. Our analysis shows that reactive astrogliosis is an important cellular reaction to brain insults associated with circulatory arrest. We have demonstrated that the acute reactive response is altered in astrocytes that developed under hypoxic conditions. Finally, the present study has demonstrated that preoperative hypoxia diminishes reactive astrogliosis, thereby contributing to increased white-matter apoptosis after insults associated with CPB and HCA.

As a consequence of improved survival after neonatal surgery for severe and/or complex CHD, one of the most important current challenges is to improve neurobehavioral deficits that frequently occur in children with CHD. ${ }^{1}$ Brain immaturity and white-matter injury are common in CHD neonates at the time of birth, most likely secondary to a reduction in fetal cerebral oxygen delivery resulting from altered fetal circulation. ${ }^{9}$ Important clinical MRI studies have demonstrated that newly developed postoperative white-matter injury is significantly associated with preoperative brain immaturity.

White matter refers to areas that have a preponderance of axons that connect various areas of the brain. Impairment of neural connectivity, owing to white-matter injury, is associated with a wide range of neurologic dysfunction, including attention deficit, hyperactivity, visual-spatial 
and perceptual problems, executive dysfunction, impairment of working memory, and verbal dysfunction. ${ }^{11,26}$ These impairments are quite similar to deficits observed in school-aged children who have CHD. ${ }^{27-29}$

Altered white-matter microstructure has been identified recently in adolescents who have $\mathrm{CHD},{ }^{30,31}$ in whom deficits of cognitive and behavioral functions have been well documented. ${ }^{28,29}$ Furthermore, premature birth is well known to be associated with alterations of the white-matter microstructure that persist into later life. ${ }^{32}$ Therefore, abnormal white-matter development early in life likely accounts for many of the neurobehavioral deficits observed in CHD. ${ }^{7}$

Insights into these mechanisms would allow for prevention and/or development of effective treatment for neonatal white-matter injury in patients who have CHD. ${ }^{7}$ Our previous studies have shown that preoperative hypoxia causes increased vulnerability of white-matter oligodendrocytes to insults associated with $\mathrm{CPB}$ and HCA. ${ }^{15}$ In particular, we have observed increased susceptibility of oligodendrocyte progenitors and mature oligodendrocytes after ischemia-reperfusion/reoxygenation injury. ${ }^{15}$ Within the known oligodendrocyte developmental stages (1. progenitor; 2 . pre-oligodendrocyte; 3 . immature oligodendrocyte; 4 . mature oligodendrocyte), the susceptibility of pre-oligodendrocytes to oxidative stress, hypoxia, and CPB-induced insults has been well recognized in other animal models, including rodents, fetal sheep, and piglets. $^{24,33,34}$ However, little information is available regarding the increased vulnerability at other stages, such as progenitor and mature oligodendrocyte to brain insults.

Here, we have demonstrated that reactive astrogliosis is an important cellular reaction to hypothermic ischemiareperfusion/reoxygenation. We found that astrocytes that developed under hypoxia did not react to insults associated with HCA. Because astrocytes play a central role in brain protection, ${ }^{18}$ this altered astrocyte response to insults may result in increased susceptibility of oligodendrocyte progenitors and mature oligodendrocytes after prolonged hypoxia. Indeed, lack of astrogliosis is associated with increased white-matter apoptosis after preoperative hypoxia in the present study, suggesting for the first time that altered astrocyte response is an important cellular mechanism underlying postoperative white-matter injury in the neonate and young infant with an immature brain, owing to in utero hypoxia.

The underlying mechanism responsible for the alteration of astrocyte reaction after prolonged hypoxia is not fully understood. With a mouse hypoxia model, however, Raymond and colleagues ${ }^{12}$ demonstrated that hypoxic injury involves a reduction in glutamate transporter expression on astrocytes, which likely leads to excess glutamate in the extracellular space. In addition, chronic hypoxia caused attenuation of Janus kinase/signal transducer and activator of transcription signaling, resulting in an immature astrocyte phenotype. This signaling is a potential therapeutic target to restore normal glutamate transporter expression and uptake of glutamate after prolonged hypoxia. For the development of molecular targets, further studies are needed to define how this signaling pathway regulates glutamate-aspartate transporter expression. We hope future studies will establish a novel pharmacologic approach that restores the protective function of astrocytes in immature white matter, thereby reducing postoperative white-matter injury in the neonate with CHD.

Brains of newborns with CHD are characterized by microcephaly and decreased maturation. ${ }^{35}$ The mouse model used in the present study has displayed a significant reduction, compared with normoxic controls, in gray- and white-matter volume (microcephaly) after hypoxic exposure. ${ }^{11}$ In the neonate with CHD, a simple scoring system for brain MRIs, the "total maturation score," has been used as a measure of brain immaturity, and myelination is 1 of 4 criteria in the system. Prolonged hypoxia in the mouse brain additionally results in significant hypomyelination (low level of myelination), compared with controls. ${ }^{13}$ Finally, we have demonstrated that mice after hypoxia displayed significant sensorimotor behavioral deficits, ${ }^{13}$ which are the most common neurologic deficits seen in children with CHD. ${ }^{7,28}$ These findings suggest that several cellular events in the fetal human brain with CHD can be reproduced in the developing mouse brain under chronic hypoxia.

Although mouse models provide significant advantages: low cost, large litter sizes, genetic/molecular manipulation, and sophisticated neurobehavioral assays, studies of white-matter injury using a mouse model have definitive limitations. For instance, the rodent brain has a simple cortex, compared with the highly evolved, gyrencephalic human neocortex. In addition, white matter occupies approximately $50 \%$ of the total brain volume in the human brain, but only $15 \%$ in rodents. Therefore, to translate findings obtained from studies using a mouse model to clinical practice, further studies in larger-animal models, such as the fetal sheep model, are very important. ${ }^{34}$

In addition to the sheep model, the piglet brain is a powerful tool to study human brain development, because it displays a highly evolved, gyrencephalic neocortex. Furthermore, in humans, approximately $50 \%$ of piglet brain volume is white matter. We have previously investigated the developing piglet brain and demonstrated that the maturation pattern in porcine white matter displays a progression similar to that of human white-matter development. ${ }^{24}$ Therefore, future study using both a rodent model and a large-animal model will help further our understanding of cellular and molecular mechanisms underlying neurologic deficits related to CHD and subsequent cardiac surgery. 
In conclusion, we have demonstrated for the first time that astrocyte activation plays a critical role in protecting white matter against hypothermic ischemia-reperfusion/ reoxygenation using a mouse brain-slice model. The astrocyte reaction is altered after prolonged hypoxia, and thus may contribute to increased white-matter injury secondary to insults associated with $\mathrm{CPB}$ and HCA in immature white matter. Thus, restoring the neuroprotective function of astrocytes before cardiac surgery can be targeted to reduce postoperative white-matter injury in the neonate and infant who has CHD and whose brain is immature as a result of prolonged prenatal hypoxia.

\section{Conflict of Interest Statement}

Authors have nothing to disclose with regard to commercial support.

The authors thank Dr Scafidi and Dr Raymond for assistance with the hypoxia experiment, and for discussions. We thank Dr Zurakowski for assistance with the statistical analysis; and colleagues at the Center for Neuroscience Research, Children's National Medical Center, for their input and support.

\section{References}

1. Kaltman JR, Andropoulos DB, Checchia PA, Gaynor JW, Hoffman TM, Laussen PC, et al. Report of the Pediatric Heart Network and National Heart, Lung, and Blood Institute Working Group on the perioperative management of congenital heart disease. Circulation. 2010;121:2766-72.

2. Gaynor JW. Periventricular leukomalacia following neonatal and infant cardiac surgery. Semin Thorac Cardiovasc Surg Pediatr Card Surg Annu. 2004;7:133-40.

3. Miller SP, McQuillen PS, Hamrick S, Xu D, Glidden DV, Charlton N, et al. Abnormal brain development in newborns with congenital heart disease. N Engl J Med. 2007;357:1928-38.

4. Beca J, Gunn JK, Coleman L, Hope A, Reed PW, Hunt RW, et al. New white matter brain injury after infant heart surgery is associated with diagnostic group and the use of circulatory arrest. Circulation. 2013;127:971-9.

5. Heinrichs AK, Holschen A, Krings T, Messmer BJ, Schnitker R, Minkenberg R, et al. Neurologic and psycho-intellectual outcome related to structural brain imaging in adolescents and young adults after neonatal arterial switch operation for transposition of the great arteries. J Thorac Cardiovasc Surg. 2014;148: 2190-9.

6. Lynch JM, Buckley EM, Schwab PJ, McCarthy AL, Winters ME, Busch DR, et al. Time to surgery and preoperative cerebral hemodynamics predict postoperative white matter injury in neonates with hypoplastic left heart syndrome. J Thorac Cardiovasc Surg. 2014;148:2181-8.

7. Morton PD, Ishibashi N, Jonas RA, Gallo V. Congenital cardiac anomalies and white matter injury. Trends Neurosci. 2015;38:353-63.

8. McQuillen PS, Miller SP. Congenital heart disease and brain development. Ann N Y Acad Sci. 2010;1184:68-86.

9. Sun L, Macgowan CK, Sled JG, Yoo SJ, Manlhiot C, Porayette P, et al. Reduced fetal cerebral oxygen consumption is associated with smaller brain size in fetuses with congenital heart disease. Circulation. 2015;131:1313-23.

10. Andropoulos DB, Hunter JV, Nelson DP, Stayer SA, Stark AR, McKenzie ED, et al. Brain immaturity is associated with brain injury before and after neonatal cardiac surgery with high-flow bypass and cerebral oxygenation monitoring. $J$ Thorac Cardiovasc Surg. 2010;139:543-56.

11. Salmaso N, Jablonska B, Scafidi J, Vaccarino FM, Gallo V. Neurobiology of premature brain injury. Nat Neurosci. 2014;17:341-6.

12. Raymond M, Li P, Mangin JM, Huntsman M, Gallo V. Chronic perinatal hypoxia reduces glutamate-aspartate transporter function in astrocytes through the Janus kinase/signal transducer and activator of transcription pathway. J Neurosci. 2011; $31: 17864-71$.
13. Scafidi J, Hammond TR, Scafidi S, Ritter J, Jablonska B, Roncal M, et al. Intranasal epidermal growth factor treatment rescues neonatal brain injury. Nature. 2014;506:230-4.

14. Murata A, Agematsu K, Korotcova L, Gallo V, Jonas RA, Ishibashi N. Rodent brain slice model for the study of white matter injury. J Thorac Cardiovasc Surg. 2013;146:1526-33. e1.

15. Agematsu K, Korotcova L, Scafidi J, Gallo V, Jonas RA, Ishibashi N. Effects of preoperative hypoxia on white matter injury associated with cardiopulmonary bypass in a rodent hypoxic and brain slice model. Pediatr Res. 2014;75:618-25.

16. Barres BA. The mystery and magic of glia: a perspective on their roles in health and disease. Neuron. 2008;60:430-40.

17. Sofroniew MV. Molecular dissection of reactive astrogliosis and glial scar formation. Trends Neurosci. 2009;32:638-47.

18. Cambron M, D'Haeseleer M, Laureys G, Clinckers R, Debruyne J, De Keyser J. White-matter astrocytes, axonal energy metabolism, and axonal degeneration in multiple sclerosis. J Cereb Blood Flow Metab. 2012;32:413-24.

19. Back SA. Cerebral white and gray matter injury in newborns: new insights into pathophysiology and management. Clin Perinatol. 2014;41:1-24.

20. Craig A, Ling Luo N, Beardsley DJ, Wingate-Pearse N, Walker DW, Hohimer AR, et al. Quantitative analysis of perinatal rodent oligodendrocyte lineage progression and its correlation with human. Exp Neurol. 2003;181: $231-40$.

21. Clouchoux C, du Plessis AJ, Bouyssi-Kobar M, Tworetzky W, McElhinney DB, Brown DW, et al. Delayed cortical development in fetuses with complex congenital heart disease. Cereb Cortex. 2013;23:2932-43.

22. Miyake T, Hattori T, Fukuda M, Kitamura T, Fujita S. Quantitative studies on proliferative changes of reactive astrocytes in mouse cerebral cortex. Brain Res. 1988:451:133-8.

23. Pekny M, Nilsson M. Astrocyte activation and reactive gliosis. Glia. 2005;50: 427-34.

24. Ishibashi N, Scafidi J, Murata A, Korotcova L, Zurakowski D, Gallo V, et al. White matter protection in congenital heart surgery. Circulation. 2012;125: 859-71.

25. Sakamoto T, Zurakowski D, Duebener LF, Lidov HG, Holmes GL, Hurley RJ, et al. Interaction of temperature with hematocrit level and $\mathrm{pH}$ determines safe duration of hypothermic circulatory arrest. J Thorac Cardiovasc Surg. 2004; 128:220-32.

26. Fields RD. White matter in learning, cognition and psychiatric disorders. Trends Neurosci. 2008:31:361-70.

27. Wernovsky G. Current insights regarding neurological and developmental abnormalities in children and young adults with complex congenital cardiac disease. Cardiol Young. 2006;16(Suppl 1):92-104.

28. Bellinger DC, Wypij D, duPlessis AJ, Rappaport LA, Jonas RA, Wernovsky G, et al. Neurodevelopmental status at eight years in children with dextrotransposition of the great arteries: the Boston Circulatory Arrest Trial. J Thorac Cardiovasc Surg. 2003;126:1385-96.

29. Bellinger DC, Wypij D, Rivkin MJ, DeMaso DR, Robertson RL Jr, DunbarMasterson C, et al. Adolescents with d-transposition of the great arteries corrected with the arterial switch procedure: neuropsychological assessment and structural brain imaging. Circulation. 2011;124:1361-9.

30. Rivkin MJ, Watson CG, Scoppettuolo LA, Wypij D, Vajapeyam S, Bellinger DC, et al. Adolescents with d-transposition of the great arteries repaired in early infancy demonstrate reduced white matter microstructure associated with clinical risk factors. J Thorac Cardiovasc Surg. 2013;146:543-9.e1.

31. Rollins CK, Watson CG, Asaro LA, Wypij D, Vajapeyam S, Bellinger DC, et al. White matter microstructure and cognition in adolescents with congenital heart disease. J Pediatr. 2014;165:936-44. e1-2.

32. Ment LR, Hirtz D, Huppi PS. Imaging biomarkers of outcome in the developing preterm brain. Lancet Neurol. 2009;8:1042-55.

33. Back SA, Han BH, Luo NL, Chricton CA, Xanthoudakis S, Tam J, et al. Selective vulnerability of late oligodendrocyte progenitors to hypoxia-ischemia. J Neurosci. 2002;22:455-63.

34. Riddle A, Luo NL, Manese M, Beardsley DJ, Green L, Rorvik DA, et al. Spatial heterogeneity in oligodendrocyte lineage maturation and not cerebral blood flow predicts fetal ovine periventricular white matter injury. J Neurosci. 2006;26: 3045-55.

35. Gaynor JW. The encephalopathy of congenital heart disease. J Thorac Cardiovasc Surg. 2014;148:1790-1.

Key Words: white matter, hypoxia, astrocyte 


\section{APPENDIX E1. METHODS Preoperative Hypoxia}

The hypoxic rearing began on day 3 and continued until day 11 in a hypoxic chamber system, to reproduce the preoperative hypoxic state (prehypoxia) of the CHD fetus (Figure 1, $B$ ). ${ }^{\mathrm{E} 1, \mathrm{E} 2}$ The maturation stage from day 3 to day 11 in the mouse white matter is equivalent developmentally to the third trimester in humans. ${ }^{\mathrm{E} 3}$ A recent clinical magnetic resonance imaging study showed that during the third trimester, a progressive and significant decline occurs in gestational age-adjusted white-matter volume in CHD fetuses, relative to healthy controls. ${ }^{\mathrm{E} 4}$ During the experiment, the oxygen concentration was maintained, monitored, and recorded continuously, with sensors placed inside the chamber to achieve a level of $10.5 \% \pm 0.5 \%$ (Pro-Ox Model 360, BioSpherix). Nitrogen gas was used to displace the oxygen and maintain hypoxic conditions. The temperature and humidity were monitored, and the parameters for each of these inside the chamber were similar to those in the normoxic condition. Strain-matched and age-matched mice reared in normal oxygen levels were used to simulate a preoperative normoxic condition (prenormoxia).

\section{Brain Slice Experiment}

Brains were collected from transgenic mice at day 11 and dissected out into ice-cold 95\%-oxygenated, modified, artificial cerebrospinal-fluid slicing solution, composed of the following: $(\mathrm{mM})$ : $87 \quad[\mathrm{NaCl}]$, $2.5[\mathrm{KCl}], 3\left[\mathrm{MgCl}_{2}\right], 0.5\left[\mathrm{CaCl}_{2}\right], 1.25\left[\mathrm{NaH}_{2} \mathrm{PO}_{4}\right], 25\left[\mathrm{NaHCO}_{3}\right]$, 25 glucose, and 75 sucrose; $\mathrm{pH}=7.4$. Coronal sections of $400 \mu \mathrm{m}$ were cut using a vibratome (Leica $1200 \mathrm{VT}$ ). Slices were allowed to recover at $22^{\circ} \mathrm{C}$ in the slicing solution for 1 hour. Perfusate temperature was then gradually increased to $36^{\circ} \mathrm{C}$ during a period of 2 hours, as is the practice for electrophysiologic studies using murine brain slices. Only slices containing corpus callosum, which is a major white-matter structure in the mouse brain, were included in the experiments (2-3 per animal). The slices from 3 litter mates (6-9 per experiment) were transferred to a customized tissue chamber (Cell MicroControls, Norfolk, Va). In the closed-chamber system, brain slices were continuously perfused ( $2 \mathrm{ml} / \mathrm{min}$ ) with artificialcerebrospinal fluid composed of the following (mM): $126[\mathrm{NaCl}], 3.5[\mathrm{KCl}], 1.3\left[\mathrm{MgCl}_{2}\right], 2\left[\mathrm{CaCl}_{2}\right], 1.2\left[\mathrm{NaH}_{2} \mathrm{PO}_{4}\right]$, $25\left[\mathrm{NaHCO}_{3}\right], 10$ glucose; $\mathrm{pH}=7.4$. This fluid was saturated with $95 \%$ $\mathrm{O}_{2} / 5 \% \mathrm{CO}_{2}\left(\mathrm{PO}_{2}, 648 \pm 14 \mathrm{~mm} \mathrm{Hg} ; \mathrm{PCO}_{2}, 46.2 \pm 0.9 \mathrm{~mm} \mathrm{Hg} ; \mathrm{O}_{2}\right.$ content: $1.94 \pm 0.04 \mathrm{ml} / \mathrm{dL}$ ). A heating and cooling device (Cell MicroControls) controlled the temperature of the perfusing, artificial, cerebrospinal fluid. In addition, the bottom of the chamber itself contained a bipolar temperature-control device, which allows precise temperature control in slices.

\section{Oxygen-Glucose Deprivation}

To replicate HCA, slices were exposed to OGD, a widely applied method for the study of brain ischemia (Figure 1,C). After an initial recovery period after the slice procedure, brain slices were cooled to a temperature of $15^{\circ} \mathrm{C}, 25^{\circ} \mathrm{C}$, or $35^{\circ} \mathrm{C}$ for 30 minutes, according to the protocol. The OGD was then performed for 60 minutes, under 3 temperature settings. The OGD was achieved by changing the perfusion solution from artificial cerebrospinal fluid saturated with $95 \% \quad \mathrm{O}_{2} / 5 \%$ $\mathrm{CO}_{2}$, to glucose-free, artificial cerebrospinal fluid (supplemented with $10 \mathrm{mM}$ sucrose to maintain osmolarity) saturated with $95 \% \mathrm{~N}_{2} / 5 \% \mathrm{CO}_{2}$ $\left(\mathrm{PO}_{2}, 54.8 \pm 2.8 \mathrm{~mm} \mathrm{Hg} ; \mathrm{PCO}_{2}, 48.3 \pm 1.2 \mathrm{~mm} \mathrm{Hg} ; \mathrm{O}_{2}\right.$ content, $0.16 \pm 0.01 \mathrm{ml} / \mathrm{dL}$ ). The slice was reperfused with glucose-containing, artificial, cerebrospinal fluid saturated with $95 \% \mathrm{O}_{2} / 5 \% \mathrm{CO}_{2}$ after the period of OGD, providing ischemia-reperfusion/reoxygenation to the brain slices. In the present study, the OGD was performed under 3 hypothermic conditions using the temperature-controlled circulation system just described (Figure 1,C).

\section{Immunohistochemistry}

At the conclusion of each experiment ( 3 or 20 hours after rewarming; Figure $1, C$ ), slices were fixed in $4 \%$ paraformaldehyde in $0.1 \mathrm{M}$ phosphate buffered saline (PBS) for 1 hour at room temperature. Each slice was cryoprotected for at least 48 hours in $30 \%$ sucrose in PBS. All slices were stored at $-80^{\circ} \mathrm{C}$ until further processing. For assessment of white-matter astrocyte injury, 20- $\mu \mathrm{m}$ sections were obtained from each $400-\mu \mathrm{m}$ brain slice, using a cryotome. Sections from the outer $100 \mu \mathrm{m}$ of each slice were excluded from the assessment, to avoid tissues that may have been damaged during slice preparation. For immunohistochemistry, $20-\mu \mathrm{m}$ sections were incubated for 1 hour at room temperature with blocking solution $(10 \%$ normal goat serum, $1 \%$ bovine serum albumin, and $0.3 \%$ Tween 20 in PBS; $\mathrm{pH}=7.4$ ) and incubated at $4{ }^{\circ} \mathrm{C}$ overnight with primary antibody and carrier solution ( $1 \%$ normal goat serum, $1 \%$ bovine serum albumin, and $0.3 \%$ Tween 20 in PBS; $\mathrm{pH}=7.4$ ).

Sections were washed with PBS and incubated for 1 hour at room temperature with secondary antibody and carrier solution. Slices were washed with PBS before mounting. A well established astrocyte response to adult brain injury is to become activated and convert to a reactive phenotype, characterized by increased GFAP expression, and changes in cell morphology and proliferation rate. ${ }^{\mathrm{E} 5, \mathrm{E} 6}$ Astrocyte activation was identified using an antibody to the GFAP. ${ }^{\mathrm{E} 7}$ Cell proliferation was identified using antibodies to Ki67, and an antibody to cleaved caspase-3 was used to identify apoptosis in the white matter. ${ }^{\mathrm{E} 8}$

\section{Assessments of White-Matter Cellular Damage}

A Zeiss LSM 510 confocal laser scanning microscopic system was used for the analysis of fluorescence. Optical sections were acquired with a field depth of 5 to $10 \mu \mathrm{m}$, using a $\times 20, \times 40$, or $\times 60$ objective and the Zeiss LSM 510 software (Carl Zeiss Microimaging LLC). Four laser lines were used to image localization of fluorescein-isothiocyanate (488-nm excitation; 522/35-nm emission filter); cyanine-3 (560-nm excitation; 605/32-nm emission filter); cyanine-5 (647-nm excitation; 680/32-nm emission filter); and 4',6-diamidino-2-phenylindole (400-nm excitation). Data acquisition and processing were controlled by LSM software.

Analysis of immunofluoresence was performed on confocal z-stacks. Confocal Assistant 4.02 and National Institutes of Health Image J software (http://rsb.info.nih.gov) were used to merge images for analysis. Merged images were processed in Photoshop 7.0 (Adobe Systems, San Jose, Calif) with minimal manipulation of contrast, as described elsewhere. ${ }^{\mathrm{E} 8-\mathrm{E} 10}$ White-matter injury in astrocytes was assessed by counting $\mathrm{GFP}^{+}$caspase- $3^{+}$cell numbers in $225 \times 225 \times 20 \mu \mathrm{m}(\mathrm{X}, \mathrm{Y}, \mathrm{Z}$ planes $)$ for cell/volume quantifications. To determine cell density, the antibodypositive cells were quantified in 3 microscopic fields from the corpus callosum of each brain slice, as described elsewhere. ${ }^{\mathrm{E9}, \mathrm{E} 10}$

\section{E-References}

E1. Morton PD, Ishibashi N, Jonas RA, Gallo V. Congenital cardiac anomalies and white matter injury. Trends Neurosci. 2015;38:353-63.

E2. Scafidi J, Hammond TR, Scafidi S, Ritter J, Jablonska B, Roncal M, et al. Intranasal epidermal growth factor treatment rescues neonatal brain injury. Nature. 2014;506:230-4.

E3. Craig A, Ling Luo N, Beardsley DJ, Wingate-Pearse N, Walker DW, Hohimer AR, et al. Quantitative analysis of perinatal rodent oligodendrocyte lineage progression and its correlation with human. Exp Neurol. 2003;181: 231-40.

E4. Clouchoux C, du Plessis AJ, Bouyssi-Kobar M, Tworetzky W, McElhinney DB, Brown DW, et al. Delayed cortical development in fetuses with complex congenital heart disease. Cereb Cortex. 2013;23:2932-43.

E5. Miyake T, Hattori T, Fukuda M, Kitamura T, Fujita S. Quantitative studies on proliferative changes of reactive astrocytes in mouse cerebral cortex. Brain Res. 1988;451:133-8.

E6. Pekny M, Nilsson M. Astrocyte activation and reactive gliosis. Glia. 2005;50: 427-34. 
E7. Raymond M, Li P, Mangin JM, Huntsman M, Gallo V. Chronic perinatal hypoxia reduces glutamate-aspartate transporter function in astrocytes through the Janus kinase/signal transducer and activator of transcription pathway. J Neurosci. 2011;31:17864-71.

E8. Ishibashi N, Scafidi J, Murata A, Korotcova L, Zurakowski D, Gallo V, et al. White matter protection in congenital heart surgery. Circulation. 2012;125: 859-71.
E9. Murata A, Agematsu K, Korotcova L, Gallo V, Jonas RA, Ishibashi N. Rodent brain slice model for the study of white matter injury. J Thorac Cardiovasc Surg. 2013;146:1526-33.e1.

E10. Agematsu K, Korotcova L, Scafidi J, Gallo V, Jonas RA, Ishibashi N Effects of preoperative hypoxia on white matter injury associated with cardiopulmonary bypass in a rodent hypoxic and brain slice model. Pediatr Res. 2014;75:618-25. 

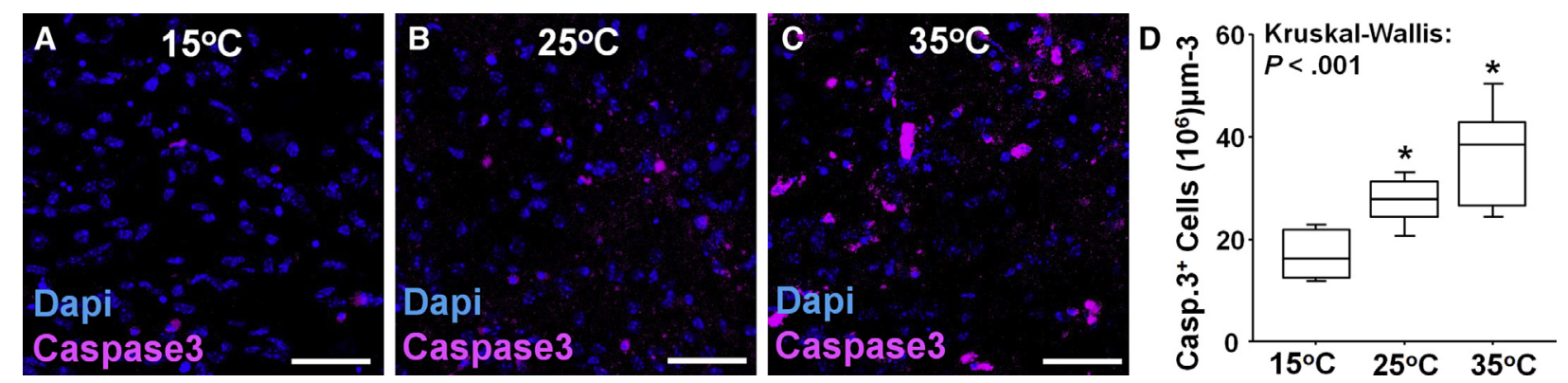

FIGURE E1. Temperature-dependent injury pattern due to OGD, after ischemia-reperfusion/reoxygenation. (A-C) Caspase- 3 immunostaining in the white matter at 20 hours after OGD at 3 temperature settings. D, White-matter caspase- $3^{+}$cell numbers at 20 hours after OGD $\left(\operatorname{control}, \mathrm{n}=9 ; 15^{\circ} \mathrm{C}, \mathrm{n}=10 ; 25^{\circ} \mathrm{C}\right.$, $\mathrm{n}=9 ; 35^{\circ} \mathrm{C}, \mathrm{n}=6$ ). Scale bar $=50 \mu \mathrm{m}$. Data are shown as box-and-whisker plots. DAPI, 4',6-diamidino-2-phenylindole; casp, caspase. $* P<.01$ versus control, Mann-Whitney $U$ test.

\begin{tabular}{lr}
\hline \multicolumn{1}{c}{ Group } & No. \\
\hline Prenormoxia $(\mathrm{n}=49)$ & \\
$3 \mathrm{~h}$ after oxygen-glucose deprivation & 7 \\
$15^{\circ} \mathrm{C}$ & 8 \\
$25^{\circ} \mathrm{C}$ & \\
$20 \mathrm{~h}$ after oxygen-glucose deprivation & 9 \\
Control & 10 \\
$15^{\circ} \mathrm{C}$ & 9 \\
$25^{\circ} \mathrm{C}$ & 6 \\
$35^{\circ} \mathrm{C}$ & \\
Prehypoxia (n $=33)$ & \\
$3 \mathrm{~h}$ after oxygen-glucose deprivation & 7 \\
$15^{\circ} \mathrm{C}$ & 7 \\
$25^{\circ} \mathrm{C}$ & \\
$20 \mathrm{~h}$ after oxygen-glucose deprivation & \\
Control & 5 \\
$15^{\circ} \mathrm{C}$ & 7 \\
$25^{\circ} \mathrm{C}$ & 7 \\
\hline
\end{tabular}

